\title{
Circulating microRNA-92a and microRNA-21 as novel minimally invasive biomarkers for primary breast cancer
}

\author{
Haiyan Si · Xiaoming Sun • Yingjian Chen • \\ Yuan Cao • Shimin Chen · Huanchun Wang • \\ Chengjin $\mathrm{Hu}$
}

Received: 13 June 2012/ Accepted: 12 September 2012/Published online: 30 September 2012

(C) The Author(s) 2012. This article is published with open access at Springerlink.com

\begin{abstract}
Purpose MicroRNAs (miRNAs) play an essential role in breast malignant tumor development and progression. The development of clinically validated biomarkers for primary breast cancer (BC) has remained an insurmountable task despite other advances in the field of cancer molecular biology. The objective of this study is to investigate the differential expression of miRNAs and the potential of circulating microRNAs as novel primary breast cancer biomarkers.

Methods Our analyses were performed on 48 tissue and 100 serum samples of patients with primary BC and a set of 20 control samples of healthy women, respectively. The relative expression of ten candidate miRNAs (miR-106b, miR-125b, miR-17, miR-185, miR-21, miR-558, miR-625, miR-665, miR-92a, and miR-93) from the results of four bioinformatics approaches and literature curation was measured by real-time quantitative reverse transcription PCR (qRT-PCR).

Results The level of miR-92a was significantly lower, while miR-21 was higher, as previous reports, in tissue and serum samples of $\mathrm{BC}$ than that of healthy controls $(p<0.001)$. Logistic regression and receiver operating characteristic curve analyses revealed the significant and independent value $(p<0.001)$ of the miR-92a and miR-21 expression quantification in serums. Moreover, the
\end{abstract}

H. Si and X. Sun contributed equally to this work.

H. Si · X. Sun · Y. Chen - Y. Cao - S. Chen ·

H. Wang · C. Hu $(\square)$

Department of Laboratory Medicine,

Jinan General Hospital of PLA, Jinan 250031

Shandong, People's Republic of China

e-mail: hcj6289@163.com comparison with the clinicopathologic data of the BC patients showed that decreased levels of miR-92a and increased levels of miR-21 were associated with tumor size and a positive lymph node status $(p<0.001)$.

Conclusions These findings suggest that many miRNAs expressions are altered in $\mathrm{BC}$, whose expression profiling may provide a useful clue for the pathophysiological research. Circulating miR-92a has potential use as novel breast cancer biomarker, which is comparable to miR-21.

Keywords Breast cancer - microRNA - miR-92a . miR-21 - KLK5 - qRT-PCR

\section{Introduction}

Development of breast malignant tumor is complex multistep process associated with numerous genetic alterations. MicroRNAs (miRNAs) are small, non-coding RNA molecules, which modulate expression of target genes and play essential roles in biological and pathological processes of diseases (Esquela-Kerscher and Slack 2006). miRNAs regulate posttranscriptional gene expression depending upon the complementarities of their sequences with target mRNAs (Bartel 2004). Kallikrein-related peptidase 5 (KLK5) is a secreted trypsin-like serine protease, encoded by the human kallikrein gene 5 (KLK5) of the kallikrein family, under the transcriptional control of estrogens and progestins (Yousef and Diamandis 1999). It has been reported that this gene is mainly expressed in breast and brain (Yousef and Diamandis 1999; Brattsand and Egelrud 1999). The prognostic value of $K L K 5$ expression had already been demonstrated for BC (Yousef et al. 2002, 2004; Avgeris et al. 2011). In our previous work, we have confirmed that a statistically significant down-regulation of 
the $K L K 5$ expression levels was observed in the malignant breast specimens compared with the benign ones.

The diagnostic and prognostic value of $K L K 5$ has already been demonstrated in BC patients; however, miRNAs which may regulate KLK5 expression have not been identified, and whether they can serve as potential biomarkers of $\mathrm{BC}$ is still unclear. In our previous work, hundreds of miRNAs are predicted by four bioinformatics approaches including TargetScan Human 5.2, MicroCosm Targets Version 5, ExprTarget, and MIRANDA (Lewis et al. 2005; Griffiths-Jones et al. 2008; Gamazon et al. 2010; LagosQuintana et al. 2001). With the results above and literature curation, ten putative miRNAs (miR-106b, miR-125b, miR17, miR-185, miR-21, miR-558, miR-625, miR-665, miR-92a, and miR-93) are selected to validate. Numerous publications have been reported that circulating miRNAs may serve as stable blood-based biomarkers in carcinomas (Schwarzenbach et al. 2011; Mitchell et al. 2008; Heneghan et al. 2010). Therefore, we detect the expression levels of the ten miRNAs in the tissue and serum samples of BC patients and investigate the potential of circulating microRNAs as novel primary breast cancer biomarkers.

\section{Methods}

\section{Study subjects}

Tumor tissues, paired normal adjacent tissues (NATs), and matching serum samples were collected from 48 cases of patients with newly diagnosed breast carcinomas. Other serum samples came from 52 cases of BC patients and 20 cases of healthy controls (HC). All the samples were recruited at Jinan General Hospital of PLA from January 2009 to December 2011. The clinical stage was classified according to the American Joint Committee on Cancer (AJCC) tumor-lymph node-metastasis (TNM) classification system. This work was performed according to the guidelines of Jinan General Hospital of PLA, which abides by the Helsinki Declaration on ethical principle for medical research involving human subjects. All subjects gave informed consent to this work.

\section{Total RNA isolation}

The miRNeasy Mini Kit (Qiagen, USA) and mirVana PARIS Kit (Ambion, USA) were used to isolate the total RNA from the tissue and serum samples according to the manufacture's protocols. RNA quality and quantity were measured by Lambda Bio UV/VIS Spectrophotometer (PERKIN ELM ER, USA). The RNA samples were immediately stored at $-80{ }^{\circ} \mathrm{C}$ or converted into cDNA immediately.
miRNA quantification by qRT-PCR

SYBR green qRT-PCR assay was used for miRNA quantification. In brief, 40-500 ng of RNA containing miRNA was polyadenylated by poly $(\mathrm{A})$ polymerase and reverse transcribed to cDNA by One Step PrimeScript ${ }^{\circledR}$ miRNA cDNA Synthesis Kit (TaKaRa, China) according to the manufacturer's instructions. Twenty-microliter reverse transcriptase reactions contained $100 \mathrm{ng}$ total RNA derived from tissue or $40 \mathrm{ng}$ total RNA form serum, $10 \mu \mathrm{l}$ $2 \times$ miRNA Reaction Buffer Mix (including dNTP Mixture, $\mathrm{Mg}^{2+}$ and Universal Adaptor Primer), $2 \mu \mathrm{l} 0.1 \%$ BSA, $2 \mu \mathrm{l}$ miRNA PrimeScript ${ }^{\circledR}$ RT Enzyme Mix, and RNase Free $\mathrm{dH}_{2} \mathrm{O}$ up to $20 \mu \mathrm{l}$. The mixture was incubated at $50{ }^{\circ} \mathrm{C}$ for $60 \mathrm{~min}$ and $85^{\circ} \mathrm{C}$ for $5 \mathrm{~s}$ with XP CYCLER (BIOER, China).

Real-time quantitative PCR was performed by Roche LightCycler480 II (Roche, Switzerland) with SYBR ${ }^{\circledR}$ Premix Ex $\mathrm{Taq}^{\mathrm{TM}}$ II kit (TaKaRa, China). The miRNAspecific forward primers were designed by Primer Premier 5.0, and the sequences are shown in Table 1. The reverse primers were provided by the SYBR ${ }^{\circledR}$ Premix Ex Taq ${ }^{\mathrm{TM}}$ II kit (Uni-miR qPCR Primer). The reaction was performed at $95^{\circ} \mathrm{C}$ for $30 \mathrm{~s}$, followed by 40 cycles at $95{ }^{\circ} \mathrm{C}$ for $5 \mathrm{~s}$ and $60{ }^{\circ} \mathrm{C}$ for $20 \mathrm{~s}$, and then ramped from 65 to $95^{\circ} \mathrm{C}$ to obtain the melting curve. RNU6 was assessed as the reference control for tissue studies, and miR-16 was for serum studies. The obtained data of miRNA expression levels are calculated and evaluated by the $\triangle \mathrm{CT}$ method as follows: $\Delta \mathrm{CT}=\mathrm{Ct}$ (miRNA of interest) $-\mathrm{Ct}$ (reference of control). The relative expression of the target miRNA was calculated by the method: $(1+E)^{(-\Delta \mathrm{CT})}, E$ : amplification efficiency. The $\mathrm{Ct}$ value was the threshold cycle to detect fluorescence. Each sample was run in duplicates for analysis.

Table 1 miRNA-specific forward primer sequences

\begin{tabular}{|c|c|}
\hline Gene name & Primer sequence \\
\hline $\operatorname{miR}-106 b$ & 5'-CGTAAAGTGCTGACAGTGCAGAT-3' \\
\hline $\operatorname{miR}-125 b$ & 5'-GTCCCTGAGACCCTAACTTGTGA-3' \\
\hline $\operatorname{miR}-17$ & 5'-CAAAGTGCTTACAGTGCAGGTAG-3' \\
\hline miR-185 & 5'-TGGAGAGAAAGGCAGTTCCTGA-3' \\
\hline $\operatorname{miR}-21$ & 5'-GGCGTAGCTTATCAGACTGATGTTG-3' \\
\hline miR-558 & 5'-CGCTGAGCTGCTGTACCAAAAT-3' \\
\hline miR-625 & 5'-CCAGGGGGAAAGTTCTATAGTCC-3' \\
\hline miR-665 & 5'-ACCAGGAGGCTGAGGCCCCT-3' \\
\hline miR-92a & 5'-TATTGCACTTGTCCCGGC-3' \\
\hline miR-93 & 5'-CAAAGTGCTGTTCGTGCAGG-3' \\
\hline RNU6 & 5'-TCGTGAAGCGTTCCATATTTTT-3' \\
\hline $\operatorname{miR}-16$ & 5'-CAGCACGTAAATATTGGCG-3' \\
\hline
\end{tabular}


Statistical analysis

The statistical analysis was performed by the SPSS software package, version 17.0 (SPSS Inc. USA). Mann-Whitney $U$ test, Wilcoxon test, ANOVA, LSD analysis, Spearman-Rho test, univariate logistic regression analysis, and receiver operating characteristic (ROC) curves were used in this work. A $p$-value $<0.05$ was considered as statistically significant. All $p$ values were two-sided.

\section{Results}

miRNAs expression in the tissue samples of BC and NATs

In the present study, we examined the expression of 10 miRNAs in BC tissues and the paired NATs. With Wilcoxon test of two dependent variables, miR-185, miR-21, and miR-93 were significantly overexpressed in the tumor specimens compared with those in NATs, whereas miR125b, miR-558, miR-625, miR-665, and miR-92a were significantly down-expressed in $\mathrm{BC}(p<0.01)$. The expression of miR-106b and miR-17 in BC tissue samples were not significantly different from the NATs $(p>0.05)$ (Fig. 1).

miRNAs expression in the serum samples of $\mathrm{BC}$ and $\mathrm{HC}$

Preliminary experiments were employed to evaluate the $\mathrm{Ct}$ values of the ten miRNAs in serum samples. Seven miRNAs including miR-106b, miR-125b, miR-17, miR-185, miR-558, miR-625, and miR-665 were removed for low expression with the $\mathrm{Ct}$ value about 35 . The rest of the miRNAs including miR-21, miR-92a, and miR-93 were examined in the serum samples of BC and HC. Consistent with the aberrant expression in BC tissue samples, miR-21 and miR-92a showed similar pattern of expression change in serum samples, while miR-93 had no significant difference between the serum samples of BC and HC. The results are displayed in Fig. 2.

The relationship between miR-92a and miR-21 expressions and clinical histopathological features

The differences in expression of miR-21 and miR-92a in NATs, BC tissues of AJCC stage I, II, III were analyzed by ANOVA and LSD analysis, and the results are shown in Fig. 3. The relationship between miR-92a and miR-21 expressions and clinical histopathological features was analyzed by Mann-Whitney $U$ test, and the results are shown in Table 2. There were no significant differences between the expressions of the remained miRNAs and
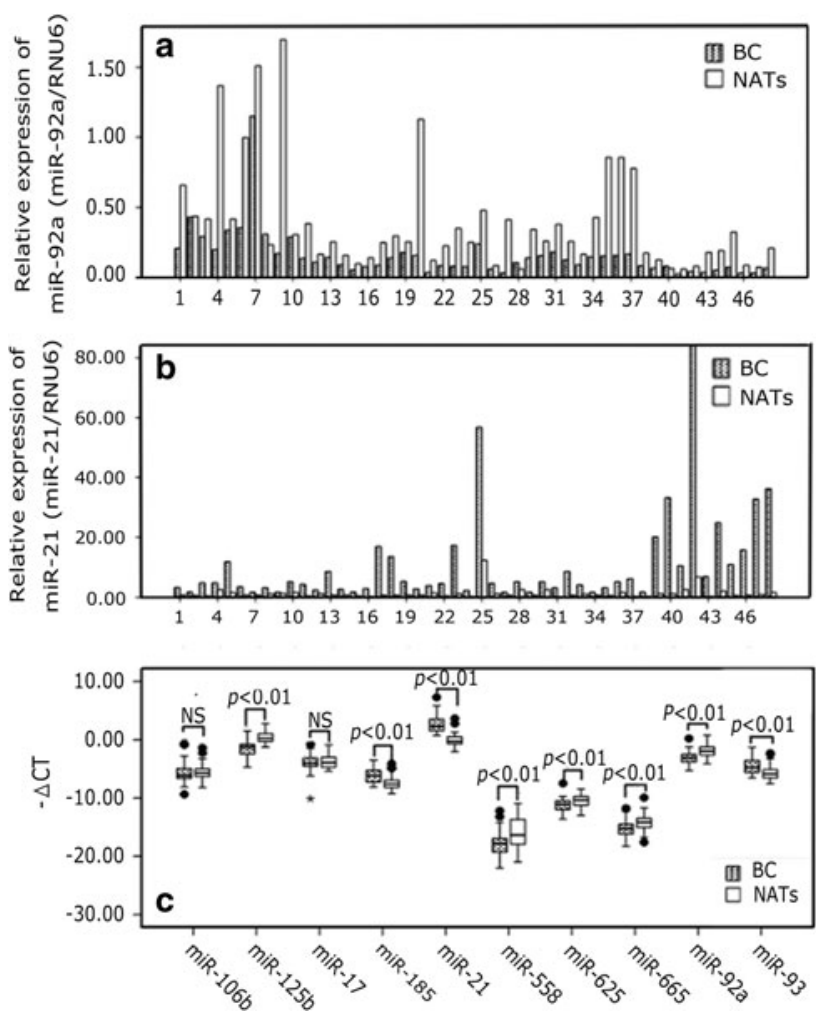

Fig. 1 Expression of miR-92a (a) and miR-21(b) in BC and matched NATs No. $1-48,(n=48)$. AJCC I, No. $1-10(n=10)$; AJCC II, No. 11-37 $(n=27)$; AJCC III, No. 38-48 $(n=11)$. Relative expression levels of miRNAs were determined by calculating the ratio between the miRNA and RNU6. $\mathbf{c}$ Relative expression levels of the ten miRNAs in BC and matched NATs are shown as box plots. The horizontal lines represent the median, the bottom and top of the boxes represent the 25 th and 75 th percentiles, respectively, and the vertical bars represent the range of data. "filled circle" over the 1.5 folds of the interquartile range; "asterisk": over the threefold of the interquartile range; $-\Delta \mathrm{CT}=\mathrm{Ct}($ reference RNU6) $-\mathrm{Ct}($ miRNA of interest); NS: $p>0.05$; The significant $p$ values of the statistical evaluations are indicated above the plots

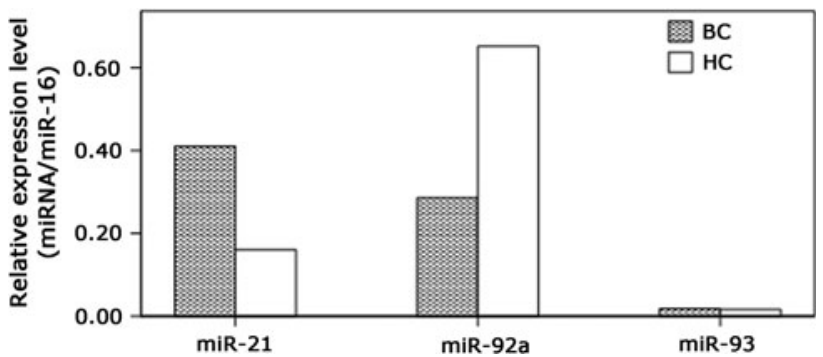

Fig. 2 Expression of miR-21, miR-92a, and miR-93 in BC and HC. Total RNA derived from the samples of BC $(n=100)$, and HC $(n=20)$ was subjected to qRT-PCR. Relative expression levels were determined by calculating the ratio between the target and the control miRNA

clinical histopathological features. The expressions of the ten miRNAs have no significant difference among the patients' ages $(p>0.05)$. 

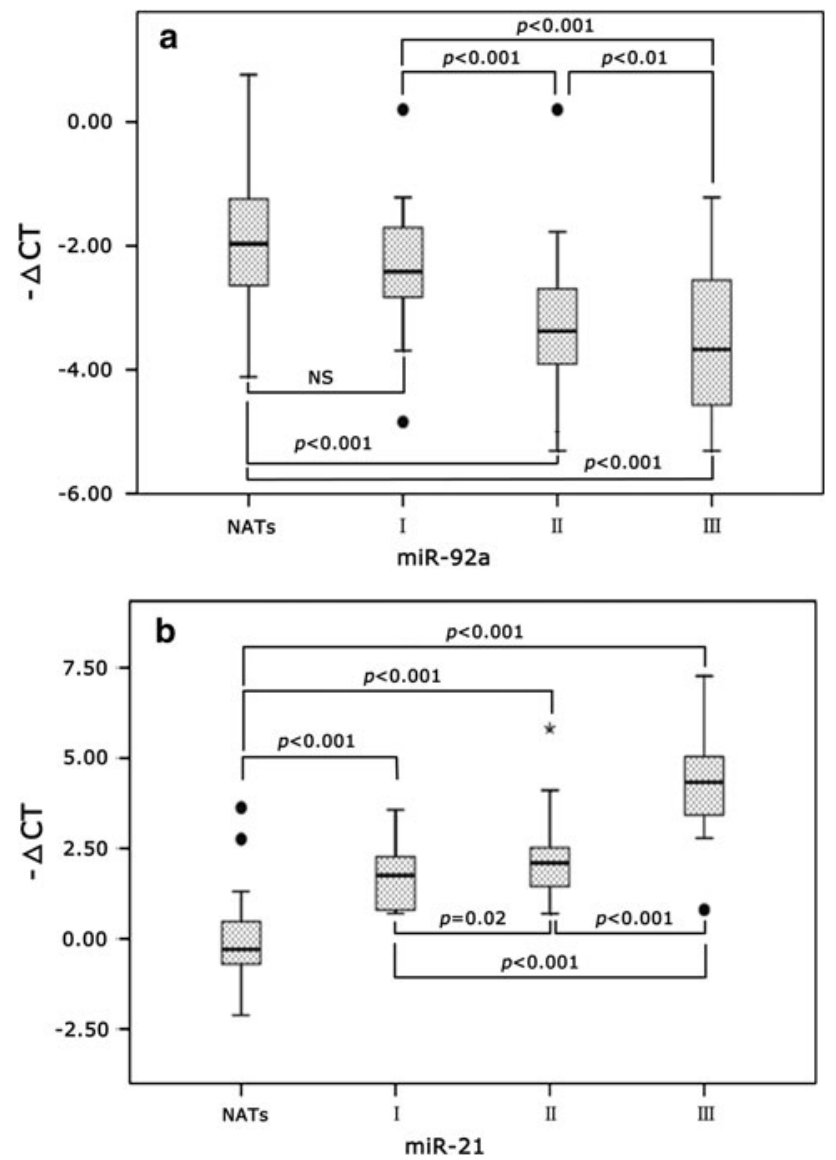

Fig. 3 Relative expressions of miR-92a (a) and miR-21 (b) in NATs and BC AJCC stages are shown as box plots. The subjects were divided into four groups based on the AJCC tumor-lymph nodemetastasis classification system, representing I $(n=10)$, II $(n=27)$, III $(n=11)$ and NATs $(n=48) .-\Delta \mathrm{CT}=\mathrm{Ct}($ reference RNU6) $-\mathrm{Ct}$ (miRNA of interest); NS: $p>0.05$. The significant $p$ values of the statistical evaluations are indicated above the plots

The correlation of miR-21 and miR-92a expression pattern between $\mathrm{BC}$ tissues and paired serums

Spearman-Rho test was carried out to compare the relative expression of miR-21 and miR-92a in 48 cases of BC tissues and paired serums. The results showed a significant correlation of miR-21 expression profiles in the tissues with those in the serums, with $r=0.61$ and miR-92a with $r=0.51(p<0.001)$.

Estimation of the predictive value of miR-92a and miR-21 expression regarding the presence of $\mathrm{BC}$

To investigate the predictive value of miR-92a and miR-21 in $\mathrm{BC}$, we measured their expression levels in serum samples of $100 \mathrm{BC}$ and $20 \mathrm{HC}$. The results by univariate logistic regression analysis showed the significant negative correlation between the miR-92a expression levels and the risk of a patient to suffer for $\mathrm{BC}(p<0.001)$. Moreover, patients with low miR-92a expression levels were at a higher risk of breast malignancy as compared to those with high miR-92a expression profiles (HR 0.07); meanwhile, patients with high miR-21 expression levels were at a higher risk of breast malignancy as compared to those with low miR-21 expression profiles (HR 10.07). ROC curve analyses also showed that both miRNAs could differentiate BC from HC with an AUC of 0.923 for miR-92a (95 \% CI $0.873-0.973)$ and 0.933 for miR-21 (95\% CI 0.889-0.977), respectively (Fig. 4).

\section{Discussion}

miRNAs are small regulatory RNAs involved in various physiological and pathophysiological processes (Osaki et al. 2008). Recently, miRNAs show great potential as diagnostic and prognostic biomarkers for BC (Lowery et al. 2008; Iorio et al. 2005; Blenkiron et al. 2007; Heneghan et al. 2011). In this work, the levels of ten candidate miRNAs (miR-106b, miR-125b, miR-17, miR-185, miR-21, miR-558, miR-625, miR-665, miR-92a, and miR-93) are quantified by qRT-PCR in tissue and serum samples of patients with BC as well as HC.

The previous study suggests that miRNAs are stable in serum by time-course and freeze-thaw cycle analyses and can escape from RNAse degradation (Schwarzenbach et al. 2011; Mitchell et al. 2008). miRNAs were for the first time described and detected in the serum of patients with diffuse B-cell lymphoma in the year 2008 (Lawrie et al. 2008). Roth et al. (2010) had confirmed that tumor-associated circulating miRNAs were elevated in the blood of BC patients and associated with tumor progression. The relative concentrations of miR-155 in serum significantly discriminated primary $\mathrm{BC}$ patients from healthy women, whereas miR-10b, miR-34a, and miR-155 discriminated metastatic disease patients from HC. Asaga et al. (2011) had proved that circulating miR-21 had diagnostic and prognostic potential in BC. miR-214 was certified as a diagnostic potential indicator in $\mathrm{BC}$ for malignant disease and metastatic (Schwarzenbach et al. 2012). Because the serum samples could be easily obtained at different time points during the course of the disease and the circulating miRNAs could be quantified by qRT-PCR (Kroh et al. 2010), circulating miRNAs as novel minimally invasive indicators have important applications in cancer detection. Serum miRNA is currently limited, due to the fact that large RNA molecules are detected to be degraded or relatively high $\mathrm{Ct}$ values in serum samples. In our work, miR-106b, miR-125b, miR-17, miR-185, miR-558, miR-625, and miR-665 have low expression levels with the $\mathrm{Ct}$ values about 35 in serums. Just miR-21, miR-92a, and miR-93 can be quantified by the qRT-PCR in serum samples. 
Table 2 The relationship between the relative expression levels of miR-92a and miR-21 and the clinical histopathological features

\begin{tabular}{|c|c|c|c|c|c|}
\hline Variable & No & $\begin{array}{l}\text { Relative expression } \\
\text { level of miR-92a } \\
(95 \% \mathrm{CI})\end{array}$ & $p$ & $\begin{array}{l}\text { Relative expression } \\
\text { level of miR-21 } \\
(95 \% \mathrm{CI})\end{array}$ & $p$ \\
\hline \multicolumn{6}{|l|}{ Tissues } \\
\hline $\mathrm{BC}$ & 48 & $0.11-0.21$ & \multirow[t]{2}{*}{$<0.01$} & $5.30-19.08$ & \multirow[t]{2}{*}{$<0.01$} \\
\hline NATs & 48 & $0.28-0.51$ & & $0.79-1.90$ & \\
\hline \multicolumn{6}{|l|}{ Serums } \\
\hline $\mathrm{BC}$ & 100 & $0.20-0.37$ & \multirow[t]{2}{*}{$<0.01$} & $0.32-0.51$ & \multirow[t]{2}{*}{$<0.0$} \\
\hline $\mathrm{HC}$ & 20 & $0.50-0.80$ & & $0.13-0.19$ & \\
\hline \multicolumn{6}{|c|}{ Tumor size } \\
\hline$<2 \mathrm{~cm}$ & 10 & $0.10-0.54$ & \multirow[t]{2}{*}{$<0.01$} & $1.12-11.40$ & \multirow[t]{2}{*}{$<0.01$} \\
\hline$\geq 2 \mathrm{~cm}$ & 38 & $0.09-0.14$ & & $5.11-22.39$ & \\
\hline \multicolumn{6}{|c|}{ Lymph node metastasis } \\
\hline Negative & 28 & $0.13-0.29$ & \multirow[t]{2}{*}{$<0.01$} & $1.88-9.81$ & \multirow[t]{2}{*}{$<0.01$} \\
\hline Positive & 20 & $0.06-0.10$ & & $5.53-36.60$ & \\
\hline \multicolumn{6}{|c|}{ Estrogen receptor } \\
\hline Negative & 17 & $0.08-0.15$ & \multirow[t]{2}{*}{$>0.05$} & $4.21-20.00$ & \multirow[t]{2}{*}{$>0.0$} \\
\hline Positive & 31 & $0.10-0.26$ & & $2.14-22.32$ & \\
\hline \multicolumn{6}{|c|}{ Progesterone receptor } \\
\hline Negative & 8 & $0.04-0.17$ & \multirow[t]{2}{*}{$>0.05$} & $3.17-36.93$ & \multirow[t]{2}{*}{$>0.05$} \\
\hline Positive & 40 & $0.11-0.23$ & & $2.85-18.38$ & \\
\hline \multicolumn{6}{|l|}{ CerbB-2 } \\
\hline Negative & 39 & $0.10-0.18$ & \multirow[t]{2}{*}{$>0.05$} & $3.18-27.22$ & \multirow[t]{2}{*}{$>0.05$} \\
\hline Positive & 9 & $0.07-0.28$ & & $3.87-12.76$ & \\
\hline
\end{tabular}

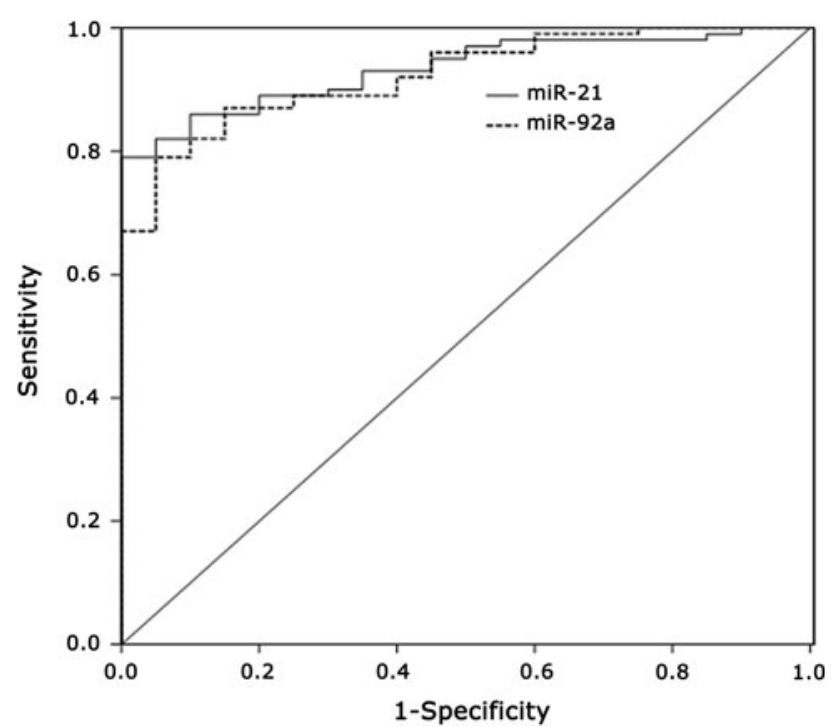

Fig. 4 miR-92a and miR-21 were plotted to discriminate $\mathrm{HC}$ and $\mathrm{BC}$ patients. miR-92a and miR-21 yield an area under the curve (AUC) value of 0.923 and 0.933 , respectively

miR-21 is one of the most significantly up-regulated miRNAs in human BC, and its expression had been associated with tumor progression and poor prognosis. In our research, miR-21 is significantly up-regulated in the BC tissues and serums, and the results indicate a trend for the association of high miR-21 expression with poor patient survival. Our results of the miR-21 are consistent with the prior studies (Asaga et al. 2011; Qian et al. 2009). Studies have demonstrated that miR-21 functions as an oncogene by targeting tumor suppressor genes including tropomyosin 1 (TPM1), programmed cell death 4 (PDCD4), and phosphatase and tensin homolog (PTEN), leading to cell proliferation and inhibition of apoptosis and regulating cancer invasion and metastasis in breast cancer (Zhu et al. 2007; Frankel et al. 2008; Yan et al. 2008).

miR-92a is one of the seven mature miRNAs (miR-17, miR-18a, miR-19a, miR-20a, miR-19b, and miR-92a) encoded by the miRNA-17-92 cluster. The miR-17-92 cluster raises first interests after several studies linked the expression of the cluster to cancer pathogenesis (Mendell 2008). It had been reported that miR-92a promoted lymph node-metastasis of human esophageal squamous cell carcinoma (ESCC) via E-Cadherin (Chen et al. 2011). Ohyashiki et al. (2011) reported that the expression level of miR-92a was down-regulated in non-Hodgkin's lymphoma (NHL). Plasma miR-92a value in NHL was extremely lower compared with that in healthy subjects, irrespective of lymphoma subtype. Tsuchida et al. (2011) determined that miR-92a was transcribed at a higher level in both adenomas and carcinoma. miR-92a directly targeted the anti-apoptotic molecule BCL-2-interacting mediator of cell 
death in colon cancer, and they indicated that miR-92a played a pivotal role in the development of colorectal carcinoma. Our, hitherto, investigations demonstrate the cancer-specific decrease in levels of miR-92a. In addition, the decreased level of miR-92a is also associated with positive lymph node status, indicating that miR-92a might be involved in cancer progression. Thus, our findings suggest that quantification of miR-92a might be suitable for detecting BC and lymph node metastases. So far, no investigation of miR-92a has been carried out in blood and tissue samples from $\mathrm{BC}$ patients.

In order to determine the correlation of miRNA expression in tissue and the matched serum samples, our results show a significant correlation of miR-21 and miR-92a expression profiles in the tissues with those in the serums (Spearman-Rho test $r=0.61$ and $0.51, p<0.01$ ), which suggests that miR-21 and miR-92a isolated from serums could reflect most of the characteristic expression patterns of their tissue counterparts and further show promise for miRNAs as blood-based biomarkers for detecting and screening breast tumors. The univariate logistic regression model discloses a statistically significant elevated risk of the patients with reduced miR-92a and increased miR-21 expression to suffer from $\mathrm{BC}$ $(p<0.001)$. As illustrated by the ROC curves with AUC values of 0.923 for miR-92a and 0.933 for miR-21, respectively, it suggests that miR-92a and miR-21 expression quantification may be used to discriminate the $\mathrm{BC}$ patients from the HC.

At present, miRNA have become the rising stars in cancer genetics. miRNAs are excellent candidates for novel molecular targeting treatments because of their ability to regulate multiple genes in molecular pathways. Chemotherapy is an important component in the treatment paradigm for cancers. However, the resistance of cancer cells to chemotherapeutic agents frequently results in the subsequent recurrence and metastasis. Recently, a new data suggest that the expression level of miR-21 in tumor tissue and plasma might be used as a biomarker to predict adjuvant platinum-based chemotherapy response and diseasefree survival in patients with non-small-cell lung cancer. Thus, it may serve as a novel therapeutic target to modulate platinum-based chemotherapy (Gao et al. 2012). Wang et al. (2012) had demonstrated that circulating miR-125b expression was associated with chemotherapeutic resistance of breast cancer. This finding has important implications in the development of targeted therapeutics for overcoming chemotherapeutic resistance in novel anticancer strategies. Trastuzumab resistance emerges to be a major issue in anti-HER2 therapy for breast cancers. Gong et al. (2011) had demonstrated that miR-21 overexpression contributes to trastuzumab resistance in HER2+ breast cancers. PTEN was identified as a miR-21 target.
Administering miR-21 antisense oligonucleotides restored trastuzumab sensitivity in the resistant breast cancer xenografts by inducing PTEN expression, whereas injection of miR-21 mimics conferred trastuzumab resistance in the sensitive breast tumors via PTEN silence. Resistance to docetaxel also occurred in $50 \%$ of breast cancer patients.

In this work, miRNAs expressions are altered in BC, whose expression profiling may provide a useful clue for the pathophysiological research. The expression level of miR92a has potential predictive value as novel breast cancer biomarker in serum samples of BC and correlates with tumor size and lymph node metastases. The study of miRNAs may lead to finding their potential for improving diagnosis, prognosis, and their impact on future therapeutic strategies.

Acknowledgments The authors thank the patients and the healthy controls who participated in this study.

Conflict of interest The authours declare that they have no conflict of interest.

Open Access This article is distributed under the terms of the Creative Commons Attribution License which permits any use, distribution, and reproduction in any medium, provided the original author(s) and the source are credited.

\section{References}

Asaga S, Kuo C, Nguyen T, Terpenning M, Giuliano AE, Hoon DS (2011) Direct serum assay for microRNA-21 concentrations in early and advanced breast cancer. Clin Chem 57:84-91

Avgeris M, Papachristopoulou G, Polychronis A, Scorilas A (2011) Down-regulation of kallikrein-related peptidase 5 (KLK5) expression in breast cancer patients: a biomarker for the differential diagnosis of breast lesions. Clin Proteomics 8:5-10

Bartel DP (2004) MicroRNAs: genomics, biogenesis, mechanism, and function. Cell 116:281-297

Blenkiron C, Goldstein LD, Thorne NP, Spiteri I, Chin SF, Dunning MJ, Barbosa-Morais NL, Teschendorff AE, Green AR, Ellis IO, Tavaré S, Caldas C, Miska EA (2007) MicroRNA expression profiling of human breast cancer identifies new markers of tumor subtype. Genome Biol 8:R214

Brattsand M, Egelrud T (1999) Purification, molecular cloning, and expression of a human stratum corneum trypsin-like serine protease with possible function in desquamation. J Biol Chem 274:30033-30040

Chen ZL, Zhao XH, Wang JW, Li BZ, Wang Z, Sun J, Tan FW, Ding DP, Xu XH, Zhou F, Tan XG, Hang J, Shi SS, Feng XL, He J (2011) microRNA-92a promotes lymph node-metastasis of human esophageal squamous cell carcinoma via E-cadherin. J Biol Chem 286:10725-10734

Esquela-Kerscher A, Slack FJ (2006) Oncomirs-microRNAs with a role in cancer. Nat Rev Cancer 6:259-269

Frankel LB, Christoffersen NR, Jacobsen A, Lindow M, Krogh A, Lund AH (2008) Programmed cell death 4 (PDCD4) is an important functional target of the microRNA miR-21 in breast cancer cells. J Biol Chem 283:1026-1033

Gamazon ER, Im HK, Duan S, Lussier YA, Cox NJ, Dolan ME, Zhang W (2010) Exprtarget: an integrative approach to predicting human microRNA targets. PLoS ONE 5:e13534 
Gao W, Lu X, Liu L, Xu J, Feng D, Shu Y (2012) MiRNA-21: a biomarker predictive for platinum-based adjuvant chemotherapy response in patients with non-small cell lung cancer. Cancer Biol Ther 13:330-340

Gong C, Yao Y, Wang Y, Liu B, Wu W, Chen J, Su F, Yao H, Song E (2011) Up-regulation of miR-21 mediates resistance to trastuzumab therapy for breast cancer. J Biol Chem 286:19127-19137

Griffiths-Jones S, Saini HK, van Dongen S, Enright AJ (2008) miRBase: tools for microRNA genomics. Nucleic Acids Res 36:D154-D158

Heneghan HM, Miller N, Lowery AJ, Sweeney KJ, Newell J, Kerin MJ (2010) Circulating microRNAs as novel minimally invasive biomarkers for breast cancer. Ann Surg 251:499-505

Heneghan HM, Miller N, Kerin MJ (2011) Circulating microRNAs: promising breast cancer biomarkers. Breast Cancer Res 13:402

Iorio MV, Ferracin M, Liu CG, Veronese A, Spizzo R, Sabbioni S, Magri E, Pedriali M, Fabbri M, Campiglio M, Ménard S, Palazzo JP, Rosenberg A, Musiani P, Volinia S, Nenci I, Calin GA, Querzoli P, Negrini M, Croce CM (2005) MicroRNA gene expression deregulation in human breast cancer. Cancer Res 65:7065-7070

Kroh EM, Parkin RK, Mitchell PS, Tewari M (2010) Analysis of circulating microRNA biomarkers in plasma and serum using quantitative reverse transcription-PCR (qRT-PCR). Methods 50:298-301

Lagos-Quintana M, Rauhut R, Lendeckel W, Tuschl T (2001) Identification of novel genes coding for small expressed RNAs. Science 294:853-858

Lawrie CH, Gal S, Dunlop HM, Pushkaran B, Liggins AP, Pulford K, Banham AH, Pezzella F, Boultwood J, Wainscoat JS, Hatton CS, Harris AL (2008) Detection of elevated levels of tumourassociated microRNAs in serum of patients with diffuse large B-cell lymphoma. Br J Haematol 141:672-675

Lewis BP, Burge CB, Bartel DP (2005) Conserved seed pairing, often flanked by adenosines, indicates that thousands of human genes are microRNA targets. Cell 120:15-20

Lowery AJ, Miller N, McNeill RE, Kerin MJ (2008) MicroRNAs as prognostic indicators and therapeutic targets: potential effect on breast cancer management. Clin Cancer Res 14:360-365

Mendell JT (2008) miRiad roles for the miR-17-92 cluster in development and disease. Cell 133:217-222

Mitchell PS, Parkin RK, Kroh EM, Fritz BR, Wyman SK, PogosovaAgadjanyan EL, Peterson A, Noteboom J, O'Briant KC, Allen A, Lin DW, Urban N, Drescher CW, Knudsen BS, Stirewalt DL, Gentleman R, Vessella RL, Nelson PS, Martin DB, Tewari M (2008) Circulating microRNAs as stable blood based markers for cancer detection. Proc Nat Acad Sci USA 105:10513-10518
Ohyashiki K, Umezu T, Yoshizawa S, Ito Y, Ohyashiki M, Kawashima H, Tanaka M, Kuroda M, Ohyashiki JH (2011) Clinical impact of down-regulated plasma miR-92a levels in non-Hodgkin's lymphoma. PLoS ONE 6:e16408

Osaki M, Takeshita F, Ochiya T (2008) MicroRNAs as biomarkers and therapeutic drugs in human cancer. Biomarkers 13:658-670

Qian B, Katsaros D, Lu L, Preti M, Durando A, Arisio R, Mu L, Yu H (2009) High miR-21 expression in breast cancer associated with poor disease-free survival in early stage disease and high TGFbeta 1. Breast Cancer Res Treat 117:131-140

Roth C, Rack B, Müller V, Janni W, Pantel K, Schwarzenbach H (2010) Circulating microRNAs as blood-based markers for patients with primary and metastatic breast cancer. Breast Cancer Res 12:R90

Schwarzenbach H, Hoon DS, Pantel K (2011) Cell-free nucleic acids as biomarkers in cancer patients. Nat Rev Cancer 11:426-437

Schwarzenbach H, Milde-Langosch K, Steinbach B, Müller V, Pantel K (2012) Diagnostic potential of PTEN-targeting miR-214 in the blood of breast cancer patients. Breast Cancer Res Treat [Epub ahead of print]

Tsuchida A, Ohno S, Wu W, Borjigin N, Fujita K, Aoki T, Ueda S, Takanashi M, Kuroda M (2011) miR-92 is a key oncogenic component of the miR-17-92 cluster in colon cancer. Cancer Sci 102:2264-2271

Wang H, Tan G, Dong L, Cheng L, Li K, Wang Z, Luo H (2012) Circulating MiR-125b as a marker predicting chemoresistance in breast cancer. PLoS ONE 7:e34210

Yan LX, Huang XF, Shao Q, Huang MY, Deng L, Wu QL, Zeng YX, Shao JY (2008) MicroRNA miR-21 overexpression in human breast cancer is associated with advanced clinical stage, lymph node metastasis and patient poor prognosis. RNA 14:2348-2360

Yousef GM, Diamandis EP (1999) The new kallikrein-like gene, KLK-L2. Molecular characterization, mapping, tissue expression, and hormonal regulation. J Biol Chem 274:37511-37516

Yousef GM, Scorilas A, Kyriakopoulou LG, Rendl L, Diamandis M, Ponzone R, Biglia N, Giai M, Roagna R, Sismondi P, Diamandis EP (2002) Human Kallikrein gene 5 (KLK5) Expression by quantitative PCR: an independent indicator of poor prognosis in breast cancer. Clin Chem 48:1241-1250

Yousef GM, Yacoub GM, Polymeris ME, Popalis C, Soosaipillai A, Diamandis EP (2004) Kallikrein gene downregulation in breast cancer. Br J Cancer 90:167-172

Zhu S, Si ML, Wu H, Mo YY (2007) MicroRNA-21 targets the tumor suppressor gene tropomyosin 1 (TPM1). J Biol Chem 282: $14328-14336$ 